\title{
Design Analysis of a 1.5kva Hybrid Power Supply for Power Reliability
}

\author{
${ }^{1}$ Ekpenyong, E.E, ${ }^{2}$ Bam, M.E and ${ }^{3}$ Anyasi, F.I \\ ${ }^{1,2,}$ Department of Electrical/Electronic Engineering, Cross River University of Technology, P.M.B 1123, \\ Calabar. Nigeria. \\ ${ }^{3}$ Department of Electrical and Electronics Engineering, Ambrose Alli University, P.M.B 14, Ekpoma, Edo State,
} Nigeria.

\begin{abstract}
Interest involves a careful design of $1.5 K V A$ hybrid power supply for power reliability. A renewable single source system for a higher power demand application is often high in cost due to sizing of the source of supply component to meat reliability requirements.

The system design is considered for the administrative office of the head of department, electrical and electronics engineering in Cross River University of technology, Calabar, Nigeria.

The system operate at minimum running cost, population free environment, noiseless, reliable and provide the convenient of a twenty-four hour power supply. With this system, energy efficiency is achieved by lowering demand using demand response, incorporating temporary and permanent load shifting by back-up and parallel mode respectively.
\end{abstract}

Keywords: Hybrid power supply, Power reliability, PV system, Inverter.

\section{Introduction}

Power supply from the national grid is inefficient and unreliable, hence the need to provide alternative source of power, [1]. Electrical power supply from renewable sources is advantageous as the increasing Electrical demand is a scientific contribution to the peak demand on the grid. As individuals and companies generate their power through renewable energy, the stress on the grid is reduced. However, there is an ongoing interest in the possibility of making wider use of renewable energy, particularly in homes, offices and industries, for the purpose of lighting, heating and powering of appliances. In most rural and sub-urban regions in Nigeria, inhabitants do not have access to electricity supply. Where the Electrical energy is available, it is not reliable; hence inhabitants resort to other forms of energy such as wood, paraffin, and diesel generators, which pollute the environment and cause harm to man and plants [2].

Nigeria is endowed with abundant renewable energy resources, like biomass, wind, small and large scale hydro with potential for hydrogen fuel, geothermal and ocean energies. Except for the large scale hydropower generating station which serves as a major source of electricity, the current state of exploitation and utilization of renewable energy resources in the country is very low[3]. The main constraint in the rapid development and diffusion of technology for the exploitation and utilization of renewable energy resources in the country is the absence of appropriate policy, regulatory and institutional framework to stimulate demand and attract investors. The comparative low quality of the systems developed and the high initial upfront also constitute barriers to the development of these systems.

The transmission network (that is from national grid) is overloaded with a wheeling capacity less than 4000MW. It has a poor voltage profile in most parts of the network, inadequate dispatch and control infrastructure, radial and fragile grid network, frequent system collapse, exceedingly high transmission losses [4]. It is a known fact that, Electric power availability enhances economic development of any society, while non availability of power or power outage creates economic hardship. The power sector is unable to match supply with demand of electric power and access to Electricity is low as about $60 \%$ of the population (approximately 80 million people in Nigeria) are not served with Electricity [5]. Electric power sustains the society in almost all ramifications; it becomes necessary for the Nigerian Government to sustain Electric power availability to its citizenry. Electricity has never been adequate to the Nigerian populace, for 115 years now, epileptic power supply and blackout is a regular phenomenon.

Solar energy is the energy transmitted from the sun in the form of electromagnetic radiation, which requires no medium for transmission. Solar energy is the most promising of the renewable energy sources in Nigeria, in view of its apparent unlimited potential. The sun radiates its energy at the rate of about $3.8 \times 10^{23} \mathrm{KW}$ per second. Most of this energy is transmitted as electromagnetic radiation which comes to about $1.5 \mathrm{KW} / \mathrm{M}^{2}$ at the boundary of the atmosphere. After traversing the atmosphere, a square metric of the earth's surface can receive as much as $1 \mathrm{KW}$ of solar power, averaging to about 0.5 over all hours of daylight. Studies relevant to the availability of the solar energy resources in Nigeria have indicated its viability for practical use. Nigeria 
receives $5.08 \times 10^{12} \mathrm{KWh}$ of energy per day from the sun and if solar energy appliances with $5 \%$ efficiency are used to cover only $1 \%$ of the country's surface area then $2.54 \times 10^{6} \mathrm{MWh}$ of electrical energy can be obtained from solar energy. The most common method of doing this is by the silicon solar cells. The amount of sunlight that strikes the earth in one minute could supply the world's energy needs for an entire year. The solar resource is so massive that it dwarfs every other resource on the planet. Grid-connected solar electric systems generate electricity that can be used throughout a home, business or office, thereby, reducing the amount of electricity needed to be purchase from the utility power company. When Photovoltaic power system generates more electricity than needed for use, the excess is fed back into the electric grid and a credit is received from the utility as the measuring meter reads backwards [6].

This work becomes necessary to demonstrate a Grid-connected solar power system for autonomous generation of electric power showing its efficiency, low running cost, reliability, silent operation, pollution free, minimal maintenance cost, automatic change-over system and an efficient payback system from the inexhaustible and free supply of the sun. The optimization of the system is based on numerical analytical modelling and the HOMER software package.

The quantity or amount of energy received from the sun depends on the positioning of the solar panel. Typically, the solar modules are mounted on the roof of a building but our decision for mounting this project's solar module on a stand-alone rack is to give room for further expansion as well as the renovation of the workshop without the interruption of proper functioning of the system. A very important consideration is how much sun the panel gets in the location chosen [6]. Solar cells loss efficiency in shaded locations, so the location for mounting our module was where it gets full sunlight for most hours of the day. The panels were oriented to the south-east to receive the maximum amount of sun [7]. The degree of tilt depends on the latitude at which they are installed. Panels installed at 0 to 15 degrees latitude normally have a 15 degree tilt; panels installed at 15 to 25 degrees latitude should have a tilt that is the same as the latitude. For each additional five degrees of latitude up to 40 degrees, an extra 5 degrees of tilt to the latitude is added. At latitudes of 40 degrees and above, 20 degrees of tilt is added latitude [8].

Solar power system captures the sun's energy with the help of photovoltaic (PV) cells in the solar modules. These cells are connected together side by side in flat panels or modules mounted on a roof or open area facing towards the sun. Energy from sunlight striking the top layer of the PV cells causes the cells to release electrons. These electrons migrate through the electrical system and back to the cells again, causing a DC electric current in the system, the same type of current produced by a battery. A device called an inverter converts the current from DC to AC to match the kind of current running through a standard electric outlet [9]. On cloudy days or when there is no sunshine, solar power system still produces electricity, although in lesser quantity, on this note, electricity is drawn from the battery bank to meet the energy needs in times of bad weather.

\section{Materials And Method}

PV Systems

Photovoltaic systems vary in complexity and depend basically on the total load demand and the availability of sunlight. The estimation here is based on hybrid principles rather than stand-alone. The major components in this system are; PV array, charge controller, inverter, battery bank, utility feeder and installation accessories. See Figure 1.

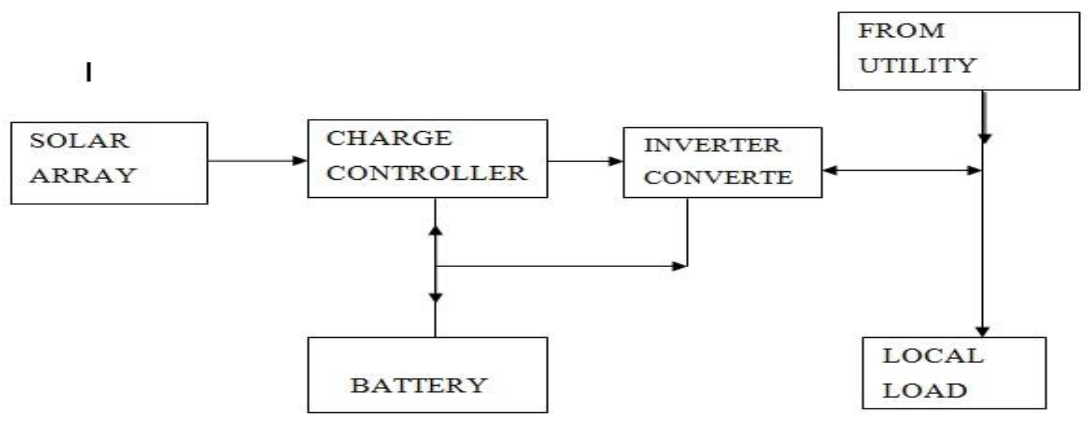

Figure 1: Basic photovoltaic system integrated with grid

Source: Non- Conventional Energy Source (G.D. Rai) 2008

\section{Pv Cell Arrangements}

PV cells are connected in parallel to achieve the desired current and in parallel to achieve the desired voltage. The optimum operating voltage of a photovoltaic cell is generally about $0.45 \mathrm{~V}$ at normal temperatures, and the current in full sunlight may be taken to be $270 \mathrm{~A} / \mathrm{m}^{2}$ [9]. A decrease or increase in the solar radiation has little effect on the voltage, but the current and power are decreased or increased proportionately. By combining a 
number of solar cells in series, the voltage is increased but the current is unchanged. However, to increase the current output at the same time, several strings would be connected in parallel as depicted in the Figure 2. Consequently, if a single cell in a string should fail, the whole string would become inoperative. The cells in the remaining strings would maintain the voltage, but the current and power output of the system would be decreased by the loss of one string of cells. A short circuit in a cell would not disable the string, although there would be a slight drop in voltage. This danger could be eliminated by including a diode, which permits current flow in one direction only, at the end of each string. Alternatively, rather than have a number of strings of cells in parallel, the current and power could be increased by locating a single string of cells at the focal line of a sun tracking, parabolic trough, concentrating collector. These results in decrease in voltage because of the inevitable higher temperature of the solar cells material, but the current would increase approximately in proportion to the concentration factor of the collector [9].

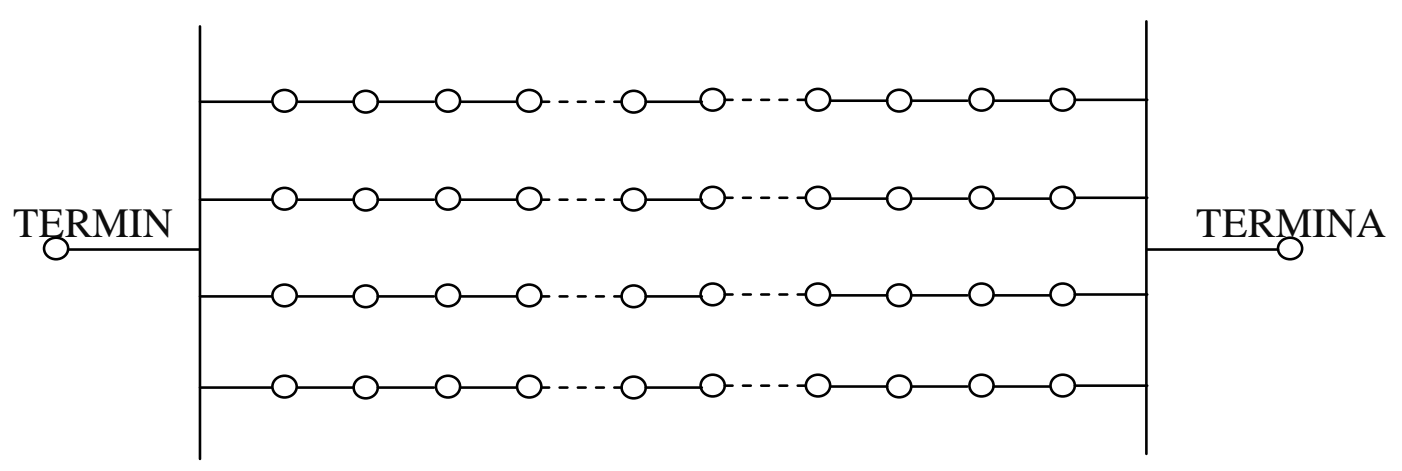

Figure.2: PV cell arrangement in series and parallel

Source: Non- Conventional Energy Source (G.D. Rai) 2008

Stand-alone PV systems: An off grid stand alone solar PV system is independent of the utility grid. Electricity from a stand-alone system is only used at the site of installation. The generated power stored in batteries is used as needed. A typical off grid house using a solar PV system is usually rated at 3 kilowatt (KW) is $15-\mathrm{Kwh} / \mathrm{day}$ and provides power only for essential devices [10]. An off grid or stand alone PV system is independent on the commercial utility power, Electricity from an off grid system is only used at the installation. The generated power is stored in battery and used as needed. The advantage of an off grid system have freedom from the commercial utility system and in the long run lower electrical cost. These disadvantages are limitations on power consumption which is dependent on the capacity of the battery bank to supply electrical power during bad weather days and being self sufficient on power.

Loads: Most common loads are $12 \mathrm{~V}, 24 \mathrm{~V}, 36 \mathrm{~V}, 48 \mathrm{~V}$, DC appliances or $220 \mathrm{~V}$ AC appliances. The estimated power consumption is given in intervals of hours or minutes, for the length of a week, month or year. If both a DC and AC system bus exist, some of the DC bus energy can be routed through the inverter to the AC loads. The loads can posses' different priorities in terms of when they need to be met by the electricity supplied. There are optional loads which can either be supplied at the specified time instant but do not have to, and then they are suitable as dump loads. There are deferrable loads, which do not have to be supplied at the specified time instant, but need to be covered within a certain time interval. Other high priority loads need to be run at the given time instant. These loads include 5 fluorescent points, 2 ceiling fans, 5 laptops, two 14" television and 1 satellite decoder [11].

Table 1 shows a typical appliances power rating, why Table 2 shows the load estimate.

Table 1: Typical Appliances Power Rating

\begin{tabular}{|l|l|}
\hline APPLIANCE NAME & POWER (WATTS) \\
\hline Air conditioner & 1350 \\
\hline Ceiling fan & 75 \\
\hline Desktop computer & 360 \\
\hline Food mixer or blender & 110 \\
\hline Heater & 1500 \\
\hline Iron & 1100 \\
\hline Lighting kitchen & 250 \\
\hline Lighting out-door & 150 \\
\hline Lighting office & 150 \\
\hline Microwave & 1450 \\
\hline
\end{tabular}


Design Analysis Of A 1.5kva Hybrid Power Supply For Power Reliability

\begin{tabular}{|l|l|}
\hline Radio-stereo & 110 \\
\hline Oven & 5000 \\
\hline Refrigerator (frost-free) & 445 \\
\hline Toaster & 1100 \\
\hline Vacuum cleaner & 700 \\
\hline Water heater (electric) & 3200 \\
\hline Television & 200 \\
\hline Deep freezer & 500 \\
\hline Laptop & 75 \\
\hline Printer & 100 \\
\hline Satellite dish & 30 \\
\hline VCR & 40 \\
\hline Kettle & 2500 \\
\hline Mobile phone charger & 15 \\
\hline Fluorescent lamp & 40 \\
\hline
\end{tabular}

Table 2: Load estimate.

\begin{tabular}{|l|l|l|l|l|l|l|}
\hline S/N & APPLIANCE & QUANTITY & $\begin{array}{l}\text { POWER } \\
\text { RATING } \\
(\mathrm{W})\end{array}$ & $\begin{array}{l}\text { HOURLY } \\
\text { USE }(\mathrm{h})\end{array}$ & $\begin{array}{l}\text { TOTAL } \\
\text { POWER } \\
(\mathrm{W})\end{array}$ & $\begin{array}{l}\text { ENERGY } \\
(\mathrm{W})\end{array}$ \\
\hline 1 & $\begin{array}{l}\text { FLOURESCENT } \\
\text { LAMP }\end{array}$ & 5 & 40 & 6 & 200 & 1200 \\
\hline 2 & FANS & 2 & 100 & 6 & 200 & 1200 \\
\hline 3 & LAPTOPS & 5 & 65 & 6 & 325 & 1950 \\
\hline 4 & 14 " TELEVISION & 2 & 62 & 6 & 124 & 744 \\
\hline 5 & $\begin{array}{l}\text { SATELLITE } \\
\text { DECODER }\end{array}$ & 1 & 100 & 6 & 100 & 600 \\
\hline 6 & SPARE & & & & 250 & 250 \\
\hline
\end{tabular}

Total power becomes 1199 watts

Total power in KVA becomes $1199 / 0.8$

$=1.498 \mathrm{KVA}$

$=1.5 \mathrm{KVA}$. This matches with the inverter size.

Energy in watt-hour $=5944 \mathrm{Wh}$

Energy in kilowatt/hour $=5.9 \mathrm{Kh}$

\section{PV System Design (PV Sizing)}

Due to the variable nature of the energy source, one of the most expensive aspects of a PV power system is the necessity to build system autonomy to provide reliable power during periods of adverse weather or increased demands. This is accomplished by over-sizing the PV array and enlarging the battery storage, which are the two most costly system components. Improved system usage and operation may be more easily achieved with a hybrid system than with a single-source application [12]. Hybridising a PV system often reduces the need for over-sizing the PV array to achieve system autonomy especially when complementarily different energy sources can be used effectively. Photovoltaic systems here are combined with battery bank and utility supply to cope with higher energy demands or in weather by extended periods of little sunshine to form the hybrid systems. The PV sizing variables to be optimized are the size of a PV panel and the number of strings in a PV array. A photovoltaic module model based on the electrical characteristics provided by the manufacturer is considered. The model calculates the power produced by a solar module using the photo conversion efficiency formulas as shown in Equations below [12].

$$
\begin{gathered}
\eta=\mathrm{P}_{S T C} / \mathrm{E}_{I N} \\
P_{\text {out }}=\eta \cdot E_{i} \cdot C_{f}
\end{gathered}
$$

Where: 
$\eta=$ Photo conversion efficiency

$P_{S T C}=$ Power at $25^{\circ} \mathrm{C}$ and $1000 \mathrm{~W} / \mathrm{m}^{2}$

$E_{i N}=1000 \mathrm{~W} / \mathrm{m}^{2}$ Standard Test Condition (STC)

$P_{\text {out }}=$ Power Output

$E_{i}=$ Effective solar irradiation impinging the cell in $W / m^{2}$

$C_{f}=$ Correction factor for $\eta$

This method is quicker and only needs the power produced by the PV module at $1000 \mathrm{~W} / \mathrm{m}^{2}$ and the irradiance level reaching the module. The method assumes that the efficiency of the solar module is constant at any irradiance level global solar radiation of Calabar (Latitude $4.97^{\circ} \mathrm{N}$, longitude $88.35^{\circ} \mathrm{E}$ and altitude $6.14 \mathrm{~m}$ above sea level) [13]. Global solar radiation data measured in $\mathrm{KWHm}^{-2}$ day ${ }^{-1}$ can be converted to $\mathrm{MJm}^{-2} \mathrm{day}^{-1}$ using a conversion factor of factor of 3.6 [14].

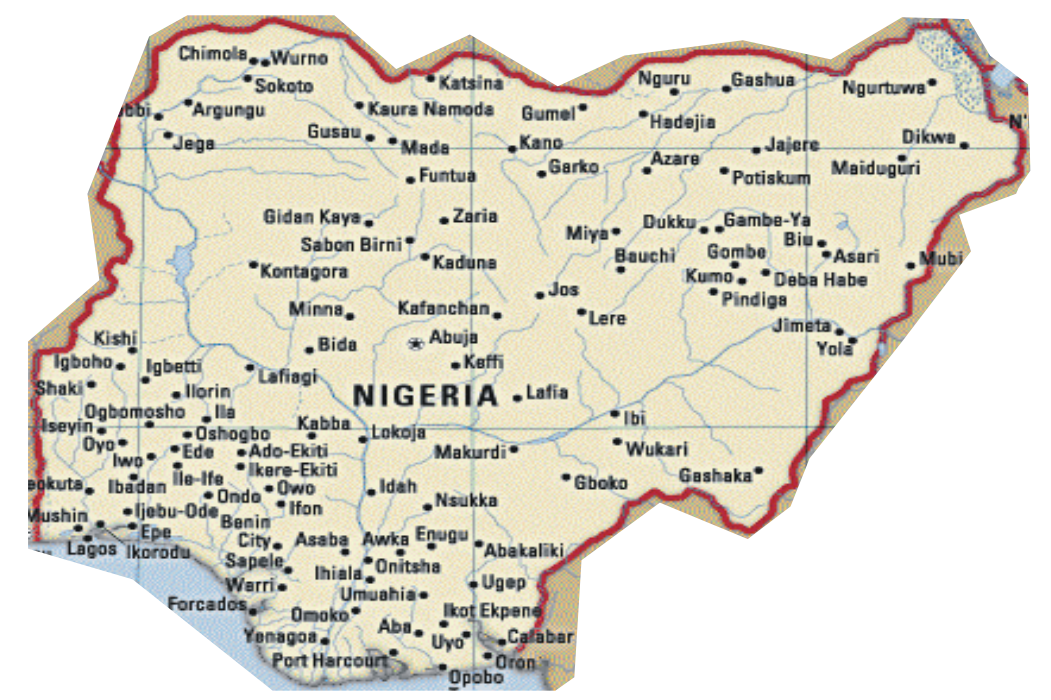

\section{Source: BritanniaEncyclopaedia}

Figure 3: Map of the Project Area.

In this work, the aim isto calculatingthe number of modules needed to supply a load of $1.5 \mathrm{KW}$ in the H.O.D's office, Department of Electrical and Electronic Engineering, Cross River University of Technology in the city of Calabar. The solar radiation during the month of January in Calabar is $14.1300 \mathrm{MJ}^{-2} \mathrm{~m}^{2}[32]$ and average sunlight hours of 4 hours [13]. The map of studied area is shown in Figure 3.

The solar radiation per hour considering 4 hours is $\left(14.1300 \mathrm{MJ}^{-2} \mathrm{~m}^{2}\right) /(4 \mathrm{~h})=981.25 \mathrm{~W} / \mathrm{m}^{2}$ per hour.

Using equation (1), the number of solar modules needed by the system using quick method can be calculated [4].

Photo conversion efficiency is calculated by

$\eta=\frac{P_{S T C}}{E_{i N}}=\frac{(110)}{(1000)}=0.11$

Now using equation (2), Power can be calculated thus;

$P_{\text {out }}=\eta \cdot E_{i} \cdot C_{f}$

$=(0.11) *(981.25) *(0.95)$

$=102.5 \mathrm{~W}$.

Now, to calculate the number of solar modules needed for the system using the quick method, we take the load power of $1498 \mathrm{~W}$ and divide it by the power generated from the solar module $(1500 \mathrm{~W}) /(102.5)=14.6$.

Meaning, 15 PV module Pss 12110 simba solar module which is equivalent to 1,650 watts PV is adequate to generate enough power to supply this load of 1.498 (1.5KVA) [13]. 


\section{Batteries In A Hybrid System}

Typically, battery efficiency is $80 \%$ requiring a battery bank capacity greater than what is actually needed [7]. Batteries periodically need servicing and have the highest potential offaults in a solar PV system. The important specifications to consider for selecting a battery are:

Capacity 6V dc, 350 Amp hour, 350 Amp/hour 20 hour Rate and 460 Amp/hour 100 hour rate.

Some basic steps to ensure good condition of your battery would be:

- Fully charge your battery before use.

- Be sure to fully tighten the connectors and properly wire the cables.

- Fasten vent caps tightly and check from time to time.

- Batteries should be wiped free of all corrosion, dust, and dirt frequently.

\section{Modelling Of The Battery Bank}

The system batteries are connected in parallel. Positive terminals are connected to positive terminals and negative terminals to negative terminals. Parallel connections are established by mutually linking the "free" positive terminals of the "series rows" on one side, and mutually linking the "free" negative terminals on the other side [15]. The number of rows to be linked in parallel depends on the number of parallel connections to be Established by the connections. See Figure 4.

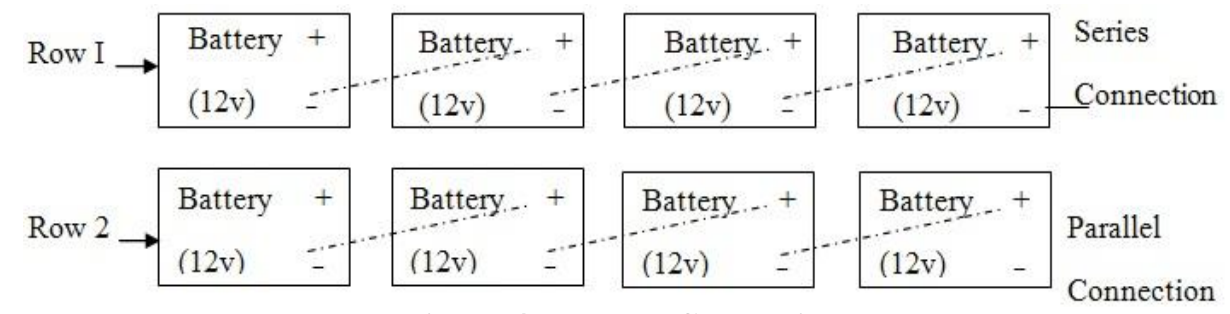

Figure 4: Parallel Connection

One set of wires - positive and negative - is connected to the charge controller (incoming current), and one set to the inverter (outgoing current) [15].The positive wires (incoming and outgoing) and the negative wire (incoming and outgoing) are best connected to diagonally opposite corners in order to equalize the charge/discharge level of the batteries (which will positively affect the sun times and battery life). The model produces a high current capacity as compared to a unit battery which is $12 \mathrm{~V}, 200 \mathrm{Ah}$. Thus by this configuration, the system rating becomes $24 \mathrm{~V}, 400 \mathrm{Ah}$. See Figure 5.

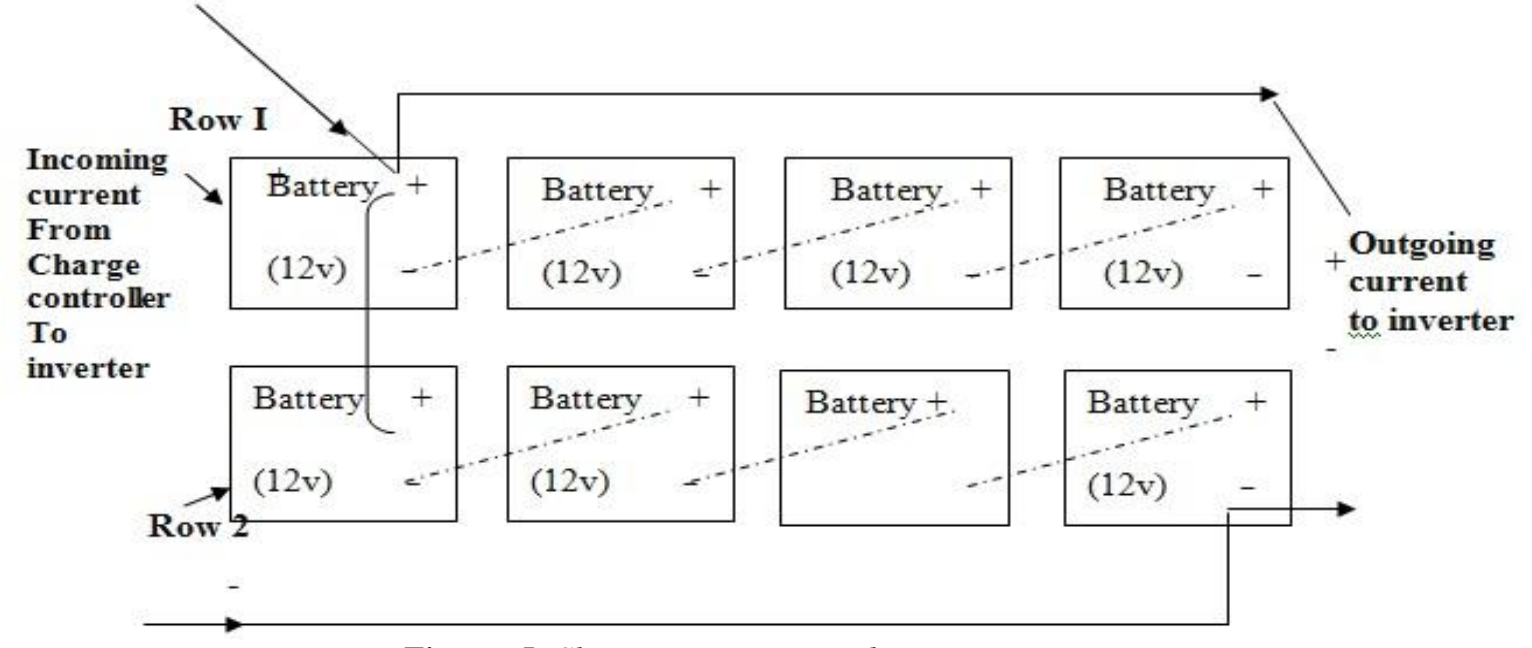

Figure .5: Showing Incoming and outgoing current

\section{Battery Sizing}

Battery sizing consists in calculating the number of batteries needed for a renewable energy system. This mainly depends on the days of autonomy desired. Days of autonomy are the number of days a battery system will supply a given load without being recharged by a PV array, utility supply or another source. If the load being supplied is not critical then 2 to 3 autonomy days are commonly used. For critical loads 5 days of autonomy are recommended [16]. A critical load is a load that must be used all the time. The battery's capacity will decrease at lower temperatures and increase at higher temperature. The battery's life increases at lower 
temperature and decreases at higher temperature. It is recommended to keep the battery's storage system at 25 ${ }^{\circ} \mathrm{C}$. At $25^{\circ} \mathrm{C}$ the derate factor is one [11].

The following procedure shows how to calculate the number of batteries needed for a hybrid energy system. Equation (3) shows how to calculate the required battery bank capacity for a hybrid renewable energy system [16].

$$
B_{R}=\frac{L_{A h / D a y} \cdot D_{S T}}{M_{D D} \cdot D_{f}}
$$

Where $L_{\text {Ah/Day }}$ is the Amp-hour consumed by the load in a day (Ah/Day)

$D_{S T}$ is the number of autonomy days

$M_{D D}$ is the maximum depth of discharge

$D_{f}$ is the derate factor

$B_{R}$ the required battery bank capacity in (Ah).

Equation (4) presents how to calculate the number of batteries to be connected in parallel to reach the Amp hours required by the system.

$$
B_{P}=\frac{B_{R}}{B_{C}}
$$

Where $B_{R}$ is the required battery bank capacity in (Ah).

$B_{C}$ is the capacity of the selected battery in (Ah)

$B_{P}$ is the number of batteries that needs to be in parallel.

Equation (5) presents how to calculate the number of batteries to be connected in series to reach the voltage required by the system.

$$
B_{S}=\frac{V_{N}}{V_{B}}
$$

Where $V_{N}$ is the DC system voltage (Volt)

$V_{B}$ is the battery voltage (Volt)

$B_{S}$ is the number of battery that needs to be in series.

The total number of batteries needed is obtained by multiplying the total number of batteries in series and the total number of batteries in parallel as shown in equation (6).

$N_{B}=B_{S} \cdot B_{P}$

Where,

$B_{S}$ is the number of batteries in Series.

$B_{P}$ is the number of batteries in parallel.

$N_{B}$ is the total number of batteries needed.

In this work, we sized a battery system that will supply $1498 \mathrm{~W}$ per day to a AC electrical load. The DC voltage of the battery system will be $24 \mathrm{~V}$. The number of autonomy days will be 4 days. The maximum depth of discharge will be $50 \%$. The batteries are kept at a temperature of $25^{\circ} \mathrm{C}$, thus, the derate factor is 1 . We choose deep cycle Acid Battery models. It has $200 \mathrm{Ah}$ at 12 Volts. The Amp-hour load of the system, take $1498 \mathrm{Wh} / \mathrm{day}$ and divide it by $24 \mathrm{~V}$, is $49.9 \mathrm{Ah} / \mathrm{day}$. Then using equation (3) to (6), we calculate the batteries required by this system.

Required Battery Capacity $B_{R}=\frac{L_{A h / D a y} \cdot D_{S T}}{M_{D D} \cdot D_{f}}$

$=[(49.9) * 4] /(0.5 * 1)$

$=399.2 \mathrm{Ah}$

$$
\equiv 400 \mathrm{Ah}
$$

Batteries in Parallel $B_{P}=\frac{B_{R}}{B_{C}}=[(399.2) / 200]=1.99=2$ 
Batteries in Series $B_{S}=\frac{V_{N}}{V_{B}}=24 / 12=2$

Total Number of Batteries $N_{B}=B_{S} \cdot B_{P}=2 * 2=4$

\section{The Inverter}

An inverter is an electrical device that converts DC to AC. The converted AC could be at any required voltage and frequency with the use of appropriate transformers, switching and control circuits [11]. Inverter in this work is used to supply AC power from DC solar panels and batteries. The Grid tie inverter can feed energy back into the distribution network because it produce alternating current with the same wave shape and frequency as supplied by the distribution system and can also turn on the hybrid system automatically in the case when utility supply switches off.The electrical inverter is a high-power electronic oscillator. It is so named because early mechanical AC to DC converters was made to work in reverse, and thus was "inverted", to convert DC to AC.The inverter performs the opposite function of a rectifier. The electricity can then be used to operate $\mathrm{AC}$ equipment like the ones that are plugged in to most house hold electrical outlets. The normal output $\mathrm{AC}$ waveform of an inverter is a sine wave with a frequency of $60 \mathrm{~Hz}$. The efficiency of converting the direct current to alternative current of most inverters today is 90 percent or more. Many inverters claim to have higher efficiencies but for this project the efficiency used is 90\%. [9] The inverter has output voltage of $220 \mathrm{~V}$ and produces a sine wave AC output signal of $60 \mathrm{~Hz}$ [17].

A Sine wave inverter produces voltage with low total harmonic distortion (normally below 3\%). It is the most expensive type, which is used when there is a need for clean sinusoidal output for some sensitive devices such as medical equipment, laser printers, stereo, etc. sine wave inverters put out a wave that is the same as that you get from the power company. Often times it is even better and cleaner. Sine wav inverters can run anything, but are also more expensive than other types. One solution to the problem of a few small appliance not working well with modified sine wave inverters is to get a large wattage of modify inverter. This gives more tolerance, and allows it to give better efficiency powered up without having to run the larger inverter to full capacity. This is the advantage of pure sine wave inverter over other type of inverters.

There are a number of topologies used in the power inverter circuits. Cheap square wave circuits suitably primarily for this kind of work may also use a push-pull converter with a step-up transformer. Most commercially manufactured models use the same basic multi-stage concept; first a switching pre-regulator (SMPS) steps up a voltage from an input source to a DC voltage corresponding to the peak value of the desired AC voltage. The output stage generates an AC. This stage usually uses a full-bridge configuration. If a half bridge is used, the DC-link voltage should be at least twice the peak of the generated output voltage. Input to output galvanic isolation is provided by either a high-frequency transformer in the SMPS switching preregulator, or by a large low-frequency output transformer [8]. If a low-frequency transformer is used, the sinusoidal voltage is generated on its primary side and transformed to the secondary side. The output voltage level can be controlled either in square-wave mode or in pulse width-modulated (PWM) mode. Sine wave circuits use PWM mode, in which the output voltage and frequency are controlled by varying the duty cycle of the high frequency pulses. Chopped signal then passes through a low pass LC-filter to supply a clean sinusoidal output. [18]. See Figure 6.

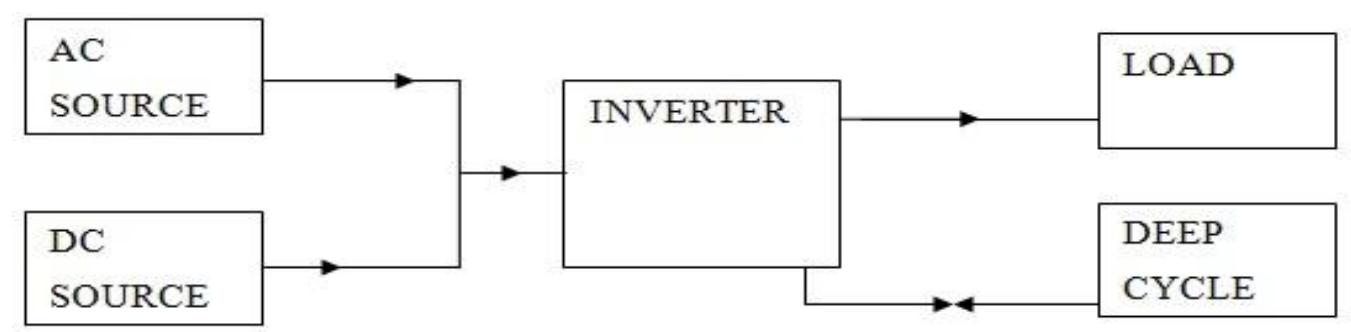

Figure 6: Block diagram of an inverter system

\section{Analytical Method}

This method can be used to select the correct size of the resistor that is suitable to produce $50 \mathrm{~Hz}$ frequency. Using the formula,

$$
\mathrm{F}=0.22 / \mathrm{RC}
$$

Where,

$\mathrm{F}=50 \mathrm{~Hz}(\mathrm{PHCN})$

$\mathrm{C}=0.1 \times 10^{-6} \mathrm{~F}$

$50=\left(0.22 \times 10^{-6} \mathrm{~F}\right) / 0.1 \times \mathrm{R}$

$5 \mathrm{R}=0.22 \times 10^{-6}$ 
$\mathrm{R}=\left(0.22 \times 10^{-6}\right) / 5$

$\mathrm{R}=44000$

$\mathrm{R}=44 \mathrm{~K} \Omega$

Hence sending switching with variable resistor size of $50 \mathrm{~K} \Omega$ and $0.1 \times 10^{-6} \mathrm{~F}$ capacitor, frequency switching of $50 \mathrm{~Hz}$ is guaranteed [19].

\section{Operation of 1.5KVA (24/220V) single phase inverter}

When the switch $\mathrm{S}_{1}$ is switched ON, the current is passed from 400Ah deep cycle battery of $24 \mathrm{~V}$ to the voltage regulator and the regulator $7805 \mathrm{IC}$ generate $5 \mathrm{~V}$ to the oscillator IC4047, this oscillator is an astablemultivibrator which gives out the square wave - signal at pin 10 and 11 [20]. This oscillation is adjusted to frequency of $50 \mathrm{~Hz}$ using the expression $\mathrm{F}=0.22 / \mathrm{RC}$, by vibration of $50 \mathrm{~K} \Omega$ variable resistor about $46 \mathrm{~K} \Omega$, the oscillation of $50 \mathrm{~Hz}$ is released to trigger the base current to flow to the transistor (PREAMP), the transistor switches at this frequency when there is base current that is limited by $100 \Omega$ resistor, this signal from emitter terminal of the transistor is amplified and drive the gate of MOSFET(IRFZ150)which switches the 24V in secondary winding of centre tap transformer at $50 \mathrm{~Hz}$ frequency and the output voltage is $220 \mathrm{~V}$ at primary of the transformer which depend on turn ratio of transformer $V_{1} / V_{2}=N_{1} / N_{2}$.[20]. See Figure 7 for the complete diagram of the 1.5KVA inverter system.

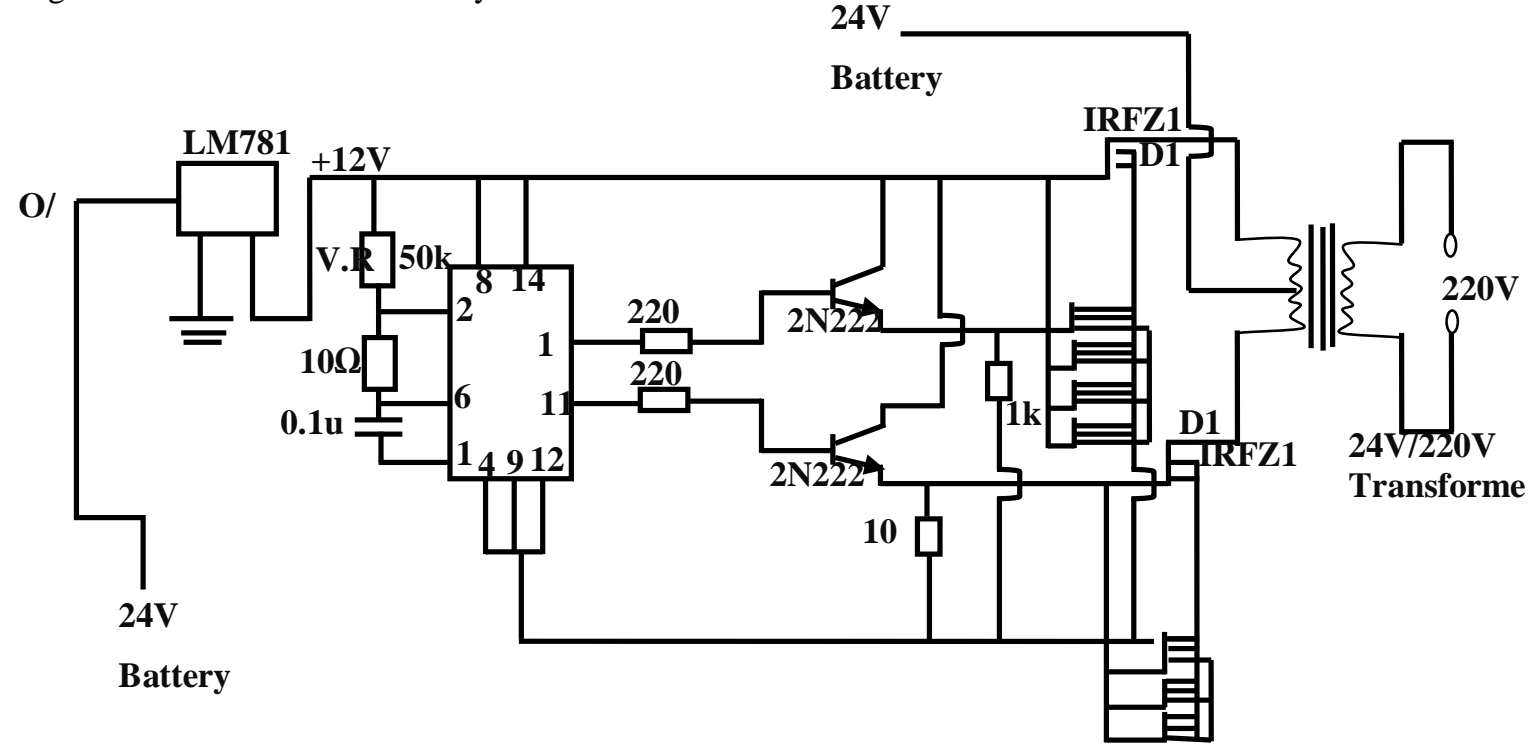

Figure 7: Circuit diagram of 1.5KVA inverter using IC CD4047 +IRFZ150

The inverter system gives out an output of steady AC voltage which makes it suitable to be used in powering sensitive electronics (equipment) like the ones used in this project. This inverter uses 3 - stage chargers, so it can be left powered up all the time because of the inbuilt power relay. Meaning that, when running from $\mathrm{AC}$, the power feeds through an inverter, at the same time, some power is being tapped for the battery charger. If the AC power goes out, the inverter automatically switches to battery power. In most cases it is difficult to notice it but for a light flicker, it is so fast because of the two transistor analogy of a thyristor which is part of the circuit. This system is designed to work automatically, it does not require anyone to be employed to physically turn it ON/OFF before it can charge the battery and at the same time, when required; supplies current to the appliances.

\section{Inverter Design}

The solar inverter is a critical component of an entire solar energy system. It performs the conversion of the variable DC output of the PV cells into a clean sinusoidal $50 \mathrm{~Hz}$ [11] current suitable for supplying the commercial electrical grid or local electrical network.Inverters are usually sized according to the maximum required continuous power output. Most inverters are capable of handling three to six times more power than their rated size for short periods of time in order to accommodate surge currents which occur when starting a motor.An inverter needs to be sized to cover peak or non-surge peak load [11].

\section{Sizing of the inverter in hybrid power supply system}

Inverter sizing consists in calculating the number of inverters needed for the PV system. In small hybrid systems such as these, one inverter is enough to supply the power but for a larger hybrid system more 
inverters may be needed. When you select an inverter you must have a DC voltage equal to your inverter DC voltage and have an $\mathrm{AC}$ voltage and frequency equal to your home and utility values [12].

Equation (7) shows how to calculate the number of inverters needed for a stand- alone hybrid system [12].

Number of Inverters required $=\frac{P_{L O A D}}{P_{\text {INVERTER }}}$

Where $P_{\text {LOAD }}$ represent the maximum continues power load your System consumes. $P_{\text {INVERTER }}$ is the maximum power that can be supplied by the inverter.

In this project, the number of inverters needed for the energy system that have an AC load of $1498 \mathrm{~W}$ is calculated. We have to select an inverter with an output power of $1199 \mathrm{~W}$ or more. The inverter model used has an output of $1500 \mathrm{~W}$ at $220 \mathrm{~V}$. Using equation (7): [12]

$$
\text { Number of Inverters required }=\frac{P_{\text {LOAD }}}{P_{\text {INVERTER }}}=1498 / 1500=0.99=1
$$

The total number of inverters needed is one.

\section{Over Voltage Regulator}

The overall operation of the voltage regulator will be discussed as follows.

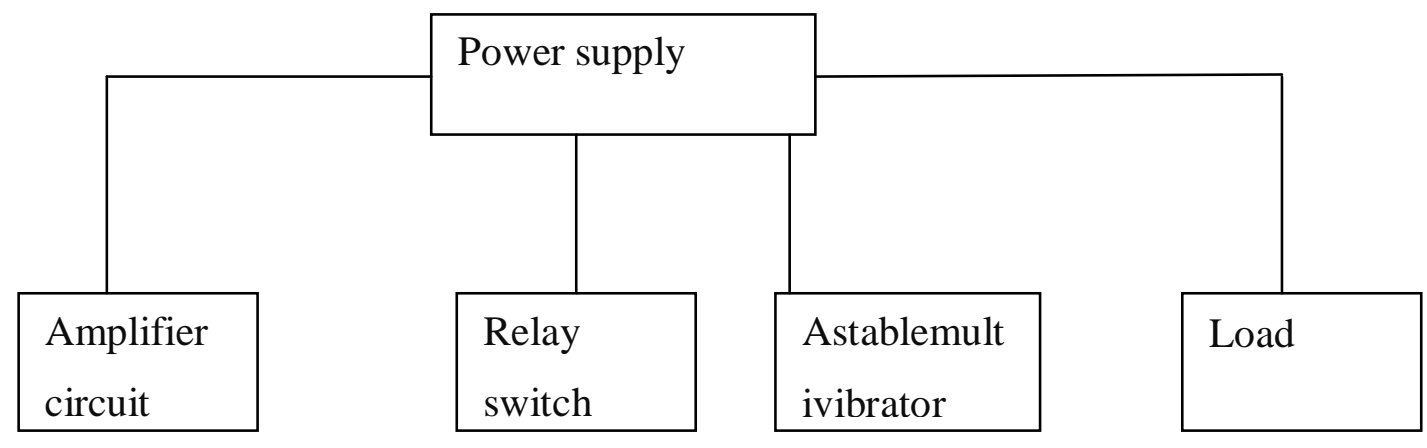

Figure 8: System's block diagram

The Power Supply Unit (PSU)

$\frac{V_{\text {out }}}{I_{c}}=R L$

Where,

$V_{\text {out }}=30 \mathrm{~V}$ and $I_{c}=3 \mathrm{~A}$

The value of RL will then be

$V_{\text {out }}=R L X I_{c}$

$$
R=\frac{30}{3}=10 \Omega
$$

\section{Filtering Capacity Calculation}

$$
C_{f}=\frac{1}{\sqrt[2]{2 \times K \times F \times R l}}
$$

$\mathrm{Fr}=$ Ripple frequency

$\mathrm{K}=$ Ripple factor

$\mathrm{RL}=$ Load Resistance

It should be noted that:

$\mathrm{Fr}=100 \mathrm{~Hz}$ (According to $\mathrm{GB}$ standard $\mathrm{F}=50 \mathrm{~Hz} \times 2)$

$\mathrm{K}=\mathrm{R}$. M. S. Ripple voltage/ DC output voltage

$\mathrm{RL}=20$ to $100 \Omega$

Chosen value

$\mathrm{Fr}=100 \mathrm{~Hz}$

R.M.S ripple voltage $=$ transfer current rating $\times$ RL

$=500 \mathrm{Mv}$

Therefore, 


$$
k=50 \times \frac{10^{-3}}{10} \quad=50 \times 10^{-2}
$$

$C_{f}=\frac{1}{\sqrt[2]{2.100 \times 50 \times 10^{-3} \times 20}}$

$=3300 \mu f$ (available value)

\section{Design Equation of an AstableMultivibrator (AMV)}

$F=1.44\left(R_{A}+2 R_{B}\right) C_{t}$

Where,

$\mathrm{R}_{\mathrm{A}=\text { Astable resistor }}$

$\mathrm{R}_{\mathrm{B}}=$ Biasing resistor

$\mathrm{C}_{\mathrm{f}}=$ Timming capacitor

$\mathrm{F}=$ frequency of oscillation

\section{IC 7805 Voltage Regulator}

In the alternative, IC $\mathbf{7 8 0 5}$ can be used for voltage regulation.The IC 7805 is basically used in this project for the voltage regulation. This IC provides a fixed positive output voltage. Although, many types of IC regulators are available, the 7800 series of IC regulators is the most popular. The last two digits in the part number indicate the DC output voltage. For example, from the data table below, the 7812 is a $+12 \mathrm{~V}$ regulator whereas the 7805 is a $+5 \mathrm{~V}$ regulator. This 7800 series provides fixed regulated voltages from $+5 \mathrm{~V}$ to $+24 \mathrm{~V}$ as shown in Table 3, [20].

Table3: The 7800 seriestable

\begin{tabular}{|l|l|}
\hline TYPE & OUTPUT \\
NUMBER & VOLTAGE \\
\hline 7805 & $+5.0 \mathrm{~V}$ \\
7806 & $+6.0 \mathrm{~V}$ \\
7808 & $+8.0 \mathrm{~V}$ \\
7809 & $+9.0 \mathrm{~V}$ \\
7812 & $+12.0 \mathrm{~V}$ \\
7815 & $+15.0 \mathrm{~V}$ \\
7818 & $+18.0 \mathrm{~V}$ \\
7824 & $+24.0 \mathrm{~V}$ \\
\hline
\end{tabular}

Source: V.K. Metha\&RohitMetha, ‘Principles of Electronics'. 2008.

Integrated circuits (IC) are preferred for voltage regulator because properties like thermal compensation, short circuit, protection and surge protection can be built into the device.

\section{Conclusion}

The system designed is to be used in conjunction with the electrical system of the office facility for use during the day or day light hour and when grid power is down. It can also work the other way, when the solar PV does not produce enough electricity, it can draw power from the grid. This is done automatically through a device that monitors the available power and switches between PV and grid power. The design of hybrid system is more complicated and expensive, but they are the most effective in providing constant and reliable electricity. The grid tie inverter feed energy back into the distribution network because it produces alternating current with the same wave shape and frequency as supplied by the distribution system and can also turn on the hybrid system automatically in the case of power failure. The aim of this work was to demonstrate that Hybridization of various renewable energy sources and battery bank is a key for system cost effectiveness and high performance than any other variant based on a single renewable source. The sizing results suggests that HOMER softwareis a powerful, efficient and flexible tool that gives the optimum and cost effective systems based on renewable source. 


\section{References}

[1] Akpama, E.J.,’Designing a photovoltaic sustained sector: a review of current practice,’domestic use of energy conference, pp 155160. 2011.

[2] M. Marvwan\& H. ImadIbrik, "Techno- economic feasibility of energy supply of remotevillages as Palestine by PV-systems, diesel generators and electric grid," renewable andsustainable energy. Reviews pp 128-138, 2006.

[3] Sambo, A.S., International centre of energy, "Energy and Development Report, Renewable Electricity Action Program," federal ministry of power and steel, Nigeria 2006.

[4] Augustine C. \&Nnabuchi M. N. "Relationship between Global Radiation And Sunshine Hours ForCalabar, Port Harcourt And Enugu, Nigeria.” International Journal of physical sciences vol. 4(4), pp.182-188, 2009.

[5] Chimeka I. U, \&chineke T. C. "Evaluating The Global Solar Energy Potential AtUturu, Nigeria."International journal of physical sciences.Vol.4(3), pp 115-119, 2011

[6] Dusabe, J.L. Munda, \&Jimoh A.A. "Small Scale Solar Energy System in Rwanda: Status. And Sustainability.”Domestic use of energy conference, pp 137-141, 2009.

[7] Rogers A. Messenger, "photovoltaic" floridaatlantic university, 2006.

[8] Retrieved from " http://en.wikipedia.org/wiki/portal:Renewableenergy."

[9] G.D. Rai, "non-conventional energy sources.”Khannapublishers 2-B, Nath market, NaiSarak Delhi-m1 10006. India.2008.

[10] Donald E.O. \& David E.C., "Utility Grid-Connected Distributed Power Systems.”National solar energy conference.ASES solar, 1996.

[11] Gabrielle Seeling-Hochmuth, "Optimisation of Hybrid Energy Systems Sizing and Operation Control." 1998.

[12] Ani, V.A. \&Nzeako A.N.," Energy Optimization at GSM Base Station Sites Located inRural Areas," international journal of energy optimization and engineering (IJEOE), 2011.

[13] Augustine C. \&Nnabuchi M. N. "Relationship between Global Radiation And. Sunshine Hours ForCalabar, Port Harcourt And Enugu, Nigeria.” International Journal of physical sciences vol. 4(4), pp.182-188, 2009.

[14] Sabbert C., \&Seeling-Hochmuth G. "Review of hybrid energy system design andperformance. "EDRC, University of Cape Town, 1997.

[15] [PVDI] solar energy international.’Photovoltaic Design and Installation Manual,'New Society Publishers, 2007.

[16] Patel M.,"Wind and Solar Power Systems," second edition, Taylor\& FrancisGroup, 2006.

[17] Igbal M.,"An Introduction to Solar Radiation.”Academy press. New York, pp. 6-51 1983.

[18] Peter Lilienthal, Tom Lambert etal, National Renewable energy laboratory."Getting Started Guide For HOMER Version 2.1". 2005.

[19] Sandia, "Stand-Alone Photovoltaic Systems." A Handbook of Recommended Design Practices. Sandia National Laboratories. 1994

[20] Paul Breeze, "Power generation technologies." 2005

[21] Semiconductor components, function IC CD4047 Datasheet, http://www.functionic cd 4047. 2012.

[22] Fairchild semiconductor, "FQP17N40Datasheet,"http://www.fairchildsemi.com/ds/fq/fqp17N40.pdf.2012

[23] V.K. Metha\&Metha."Principles of electronics"s.chad technical,2007.

[24] http://www.biomassenergycentre.org.uk/portals/page. 